\title{
VEŽIMĖLIO PRITAIKYMO SVARBA VEŽIMĖLIŲ KREPŠINIO ŽAIDĖJŲ SPECIALIESIEMS GEBĖJIMAMS
}

\author{
Kęstutis Skučas \\ Lietuvos kūno kultūros akademija, Kaunas, Lietuva
}

\begin{abstract}
Kęstutis Skučas. Socialinių mokslų daktaras. Lietuvos kūno kultūros akademijos Taikomosios fizinės veiklos katedros lektorius. Mokslinių tyrimų kryptis — taikomosios fizinès ir sportinės veiklos poveikis neigaliujų reabilitacijai, neigaliujų sportinės veiklos organizavimo ypatumai.
\end{abstract}

\section{SANTRAUKA}

Tyrimo tikslas — nustatyti vežimèlio pritaikymo svarbq vežimèliu krepšinio žaidèju specialiesiems gebejjimams. Testavimo metodu tirti 24 vežimèliu krepšinio žaidèjai, dalyvaujantys varžybose. Tiriamuju amžius 17-37 metai.

Remiantis tarptautinès vežimèliu krepšinio klasifikacijos reikalavimais, žaidèjai pagal negalios sunkumo laipsni skirstomi taip: du 1,5 balo žaidejjai, šeši - 2, du - 2,5, penki - 3, penki - 4, keturi - 4,5. Naudoti pagrindiniai vežimèliu krepšinio specialiuju gebëjimu vertinimo testai (Hedrick et al., 1994; Skučas, Stonkus, 2001). Tirtos dvieju vežimèlio padèčiu (vertikalios ir horizontalios) pritaikymo galimybès — aukštos ir žemos sèdèsenos vežimèlyje svarba žaidejju specialiesiems gebëjimams. Tuo tikslu tirti žaidejjai suskirstyti $\underline{u}$ dvi grupes: I — sunkesnès negalios (1-2,5 balo) ir II - lengvesnès (3-4,5 balo). Kiekvienos grupés žaidèjai atliko po dvi testavimu serijas žemai ir aukštai sèdèdami vežimèlyje.

Tyrimo rezultatai parodè, kad žema sèdèsena vežimèlyje lemia geresnius daugumos vežimèliu krepšinio sunkesnès negalios žaidëju specialiuju gebèjimu rodiklius, lyginant su aukštos sèdèsenos žaidëju rodikliais. Nepriklausomai nuo vežimèlio sèdynès aukščio daugelis lengvesnès negalios vežimèliu krepšinio žaidèju specialiuju gebejjimu rodikliu skyrèsi mažai. Tyrimas parodè, kad vežimèlio pagrindiniu ratu galinè padètis gerina sunkesnès negalios žaidèju anaerobinès ištvermès ir greitumo fiziniu ypatybiu raiškq. Vežimèlio pagrindiniu ratu priekinè padètis gerino sunkesnès negalios žaidèju vikrumo ir kamuolio varymo rodiklius. Vežimèlio priekiné pagrindiniu ratu padètis gerina lengvesnès negalios žaidèju anaerobinès ištvermès, vikrumo ir kamuolio varymo rodiklius.

Raktažodžiai: vežimèlio pritaikymas, vertikali ir horizontali vežimèlio padètis, aukšta ir žema sèdèsena vežimèlyje.

\section{IVADAS}

$\mathrm{V}$ ežimèlių krepšinio klasifikacinès sistemos tikslas - sudaryti sąlygas, kad įvairios negalios asmenys galètu žaisti ši žaidimą, kuris jiems yra idomus ir kuri žaisti jie yra pajėgūs (Coubariaux, 1994). Vežimèlių krepšinio klasifikacinė sistema yra pagrịsta fiziniais žaidèju gebėjimais, t. y. kaip žaidejjas vežimėlyje gali atlikti pagrindinius krepšinio veiksmus: važiuoti, apsisukti, perduoti, gaudyti, varyti kamuoli, mesti ji i krepši (Coubariaux, 1994; Molik, Kosmol, 1999). Žaidžiant vežimėlių krepšinį kaip komandi- ni žaidimą, labai svarbūs bendri tarp žaidèjų suderinti veiksmai. Norėdamas sudaryti aikštès žaidèjų penketą ir neviršyti nustatytų 14 balu̧, treneris turi daugybę galimybiu, tačiau visada privalès rinktis skirtingos negalios žaidejjus. Šalia 4 ir 4,5 balo vežimėlyje tvirtai sẻdinčių žaidejjų būtinai turi žaisti ir $1-2$ balų žaidėjai, kurių liemens stabilumas sutrikęs ir jų funkcinès galimybės žaisti vežimèlių krepšini yra skirtingos. Dauguma autorių, nagrinèjusių skirtingos negalios krepšininkų žaidimo kiekybinius ir kokybinius rodiklius, pabrěžè, kad 
sunkesnès negalios žaidėjų ( $1-2$ balų) rodikliai blogesni negu lengvesnès. Tačiau jie nenagrinėjo vežimèlio pritaikymo svarbos krepšinio žaidimo kokybei.

Vežimėlių krepšinio taisyklès numato tam tikrus vežimèlio įtaisų konstrukcijos apribojimus. Labai svarbu rasti tinkamą padètị ir pritaikyti ji kiekvienam vežimèlių krepšinio žaidejjui, atsižvelgiant $i$ jo pakenkimo tipa, negalios sunkumo laipsni, antropometrinius duomenis (Adomaitienè ir kt., 2003). Nemažai tyrimų atlikta tiriant vežimèlio varymo, kamuolio metimo biomechaninius parametrus (Brasile, 1986; Brasile, Hedrick, 1996; Abu et al., 1998; Goosey-Tolfrey et al., 2002), tačiau kaip vežimèlio pritaikymas veikia vežimèliu krepšinio žaidèjų specialiuosius gebėjimus rasti nepavyko. Tokie tyrimai galètų atskleisti vežimèlio pritaikymo galimybes norint pagerinti sunkios negalios krepšinio žaidejjų fizinius ir specialiuosius gebèjimus.

Tyrimo objektas - neigaliụjų, žaidžiančių krepšini, vežimėlio pritaikymo ypatumai.

Tyrimo tikslas: išsiaiškinti vežimèlio pritaikymo svarbą vežimèlių krepšinio žaidejjų specialiesiems gebejjimams.

\section{TYRIMO METODAI IR ORGANIZAVIMAS}

Naudoti šie tyrimo metodai: literatūros šaltinių analizé, testavimas, matematinè statistika. Testavimo metodu tirti 24 vežimėlių krepšinio žaidejjai, dalyvaujantys varžybose. Tiriamujų amžius - 17-37 metai. Remiantis tarptautine vežimėlių krepšinio klasifikacija, pagal negalios

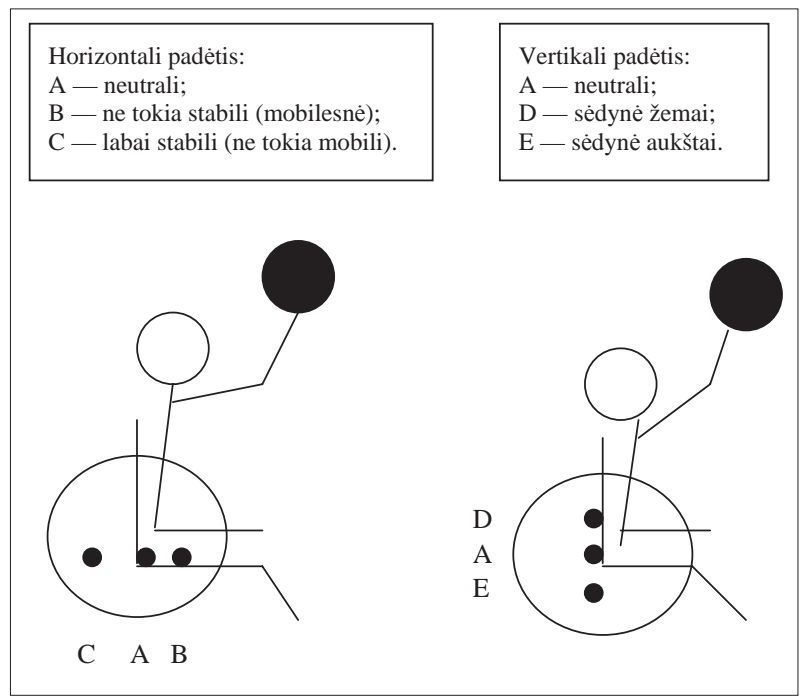

1 pav. Horizontalios ir vertikalios padèties vežimèlio pritaikymas (Abu et al., 1998) sunkumo laipsni žaidèjai skirstomi taip: du 1,5 balo žaidèjai, šeši -2 , du $-2,5$, penki -3 , penki -4 , keturi $-4,5$. Naudoti pagrindiniai vežimèlių krepšinio specialiujų gebėjimų vertinimo testai (Hedrick et al., 1994; Skučas, Stonkus, 2001). Tirtos dviejų vežimèlio padèčių (vertikalios ir horizontalios) pritaikymo galimybės — aukštos ir žemos sèdèsenos vežimėlyje (1 pav.) svarba žaidejju specialiesiems gebėjimams. Tuo tikslu tirti žaidejjai buvo suskirstyti $\mathfrak{i}$ dvi grupes: I - sunkesnès negalios ( 1 -2,5 balo) ir II — lengvesnès (3-4,5 balo). Kiekvienos grupès žaidèjai atliko po dvi testavimų serijas žemai ir aukštai sėdėdami vežimėlyje. Matematinė statistinė analizė buvo atliekama tyrimo duomenis apdorojant statistinès duomenų analizès programa SPSS 8.0. Statistinių ryšių stiprumas vertintas naudojant Stjudento $t$ kriterijų.

\section{REZULTATAI}

Testavimo rezultatai parodė: kai vežimèlio padètis horizontali (žr. 1 lent.), sunkesnès negalios žaidėjai geriau atlieka fiziniu ypatybių ir vežimèlių krepšinio žaidimo igūdžių testus, išskyrus tolimų metimų i krepši testa, kai jie sèdi žemame, o ne aukštame vežimėlyje $(\mathrm{p}<0,05)$.

Lengvesnès negalios žaidèjų daugumos testų rodikliai vežimėlyje sėdint žemai ir aukštai buvo panašūs. Statistiškai patikimai $(\mathrm{p}<0,05)$ skyrèsi tik artimų, tolimų metimų i krepši ir iš vidutinio atstumo rodikliai (2 lent.).

Žaidžiant vežimèlių krepšini, galimos kelios pagrindinių ratų padètys, kurios lemia daugumą vežimėlio mobilumo ypatybių — ratai stumiami i prieki arba atgal (Coubariaux, 1994). Atlikus tyrimą paaiškejjo, kad sunkesnès negalios vežimèlių krepšinio žaidėjai pasiekė geresniu greitumo, anaerobinès ištvermès, vikrumo rodikliu, kai vežimèlio ratų padètis buvo galinè, o artimų metimų i krepšị ir iš vidutinio atstumo - kai ratu padètis priekinè (3 lent.).

Geresni buvo lengvesnès negalios vežimèlių krepšinio žaidėjų anaerobinès ištvermès ir kamuolio varymo rodikliai naudojant priekinès ratu padèties vežimèli, kiti rodikliai panašūs (4 lent.).

\section{REZULTATU APTARIMAS}

Tyrimai parodè, kad dauguma judejjimo vežimèliu charakteristikų, fizinès ypatybės, vežimèlių krepšinio žaidimo igūdžių rodiklių priklauso nuo 


\begin{tabular}{|l|l|c|c|}
\hline \multicolumn{1}{|c|}{ Testas } & \multicolumn{1}{c|}{ Parametras } & Žema sėdèsena & Aukšta sėdėsena \\
\hline 30 s važiavimo, $m$ & Anaerobinė ištvermé & $76,82^{*} \pm 9,31$ & $69,62 \pm 7,56$ \\
\hline 20 m sprinto, s & Greitumas & $6,94^{*} \pm 0,27$ & $7,3 \pm 0,48$ \\
\hline Važiavimo aštuonetu & Vikrumas & $16,80^{*} \pm 1,82$ & $15,33 \pm 1,73$ \\
\hline $\begin{array}{l}\text { Kamuolio varymo } \\
\text { aštuonetu }\end{array}$ & $\begin{array}{l}\text { Vežimėlio ir kamuolio } \\
\text { valdymas }\end{array}$ & $15,62^{*} \pm 1,53$ & $14,67 \pm 1,09$ \\
\hline Tolimų metimu & Metimų tikslumas & $9,64 \pm 2,31$ & $9,92 \pm 2,24$ \\
\hline $\begin{array}{l}\text { Artimų metimų ir iš } \\
\text { vidutinio atstumo }\end{array}$ & Metimų tikslumas & $43,72^{*} \pm 5,38$ & $39,6 \pm 4,27$ \\
\hline $\begin{array}{l}\text { Kamuolio perdavimo } \\
\text { testas }\end{array}$ & $\begin{array}{l}\text { Kamuolio perdavimo } \\
\text { tikslumas }\end{array}$ & $29,8^{*} \pm 5,92$ & $27,2 \pm 4,25$ \\
\hline
\end{tabular}

1 lentelè. Sunkesnès negalios $(\mathbf{1}-\mathbf{2 , 5}$ balų) vežimèliụ krepšinio žaidėju specialiųjų gebẻjimų testų rodikliai pritaikius vertikalios padèties vežimèli $(\overline{\mathbf{X}} \pm \mathbf{S} \overline{\mathbf{x}})$

\begin{tabular}{|l|l|c|c|}
\hline \multicolumn{1}{|c|}{ Testas } & \multicolumn{1}{c|}{ Parametras } & Žema sėdėsena & Aukšta sėdėsena \\
\hline 30 s važiavimo, $\mathrm{m}$ & Anaerobinė ištverme & $80,92^{*} \pm 8,35$ & $81,82 \pm 7,46$ \\
\hline $20 \mathrm{~m}$ sprinto, $\mathrm{s}$ & Greitumas & $6,14^{*} \pm 0,47$ & $6,32 \pm 0,28$ \\
\hline Važiavimo aštuonetu & Vikrumas & $18,80 \pm 1,82$ & $18,33 \pm 1,73$ \\
\hline $\begin{array}{l}\text { Kamuolio varymo } \\
\text { aštuonetu }\end{array}$ & $\begin{array}{l}\text { Vežimėlio ir kamuolio } \\
\text { valdymas }\end{array}$ & $16,62 \pm 1,53$ & $15,97 \pm 1,09$ \\
\hline Tolimų metimų & Metimų tikslumas & $9,54 \pm 2,31$ & $10,98^{*} \pm 2,24$ \\
\hline $\begin{array}{l}\text { Artimų metimų ir iř } \\
\text { vidutinio atstumo }\end{array}$ & Metimų tikslumas & $46,72 \pm 5,38$ & $52,6^{*} \pm 4,27$ \\
\hline $\begin{array}{l}\text { Kamuolio perdavimo } \\
\text { testas }\end{array}$ & $\begin{array}{l}\text { Kamuolio perdavimo } \\
\text { tikslumas }\end{array}$ & $27,8 \pm 5,92$ & $28,2 \pm 4,25$ \\
\hline
\end{tabular}

Pastaba. * $-\mathrm{p}<0,05$, lyginant tos pačios grupès žaidejju, sèdinčiu aukštame ir žemame vežimèlyje, ro-

\begin{tabular}{|l|l|c|c|}
\hline \multicolumn{1}{|c|}{ Testas } & \multicolumn{1}{c|}{ Parametras } & Priekiné ratų padėtis & Galinė ratų padètis \\
\hline 30 s važiavimo, $\mathrm{m}$ & Anaerobiné ištvermé & $69,92 \pm 5,11$ & $77,82 * \pm 7,46$ \\
\hline $20 \mathrm{~m}$ sprinto, $\mathrm{s}$ & Greitumas & $7,04 \pm 0,47$ & $6,45^{*} \pm 0,28$ \\
\hline Važiavimo aštuonetu & Vikrumas & $17,80^{*} \pm 1,82$ & $16,33 \pm 1,73$ \\
\hline $\begin{array}{l}\text { Kamuolio varymo } \\
\text { aštuonetu }\end{array}$ & $\begin{array}{l}\text { Vežimėlio ir kamuolio } \\
\text { valdymas }\end{array}$ & $16,62 * \pm 1,53$ & $15,37 \pm 1,09$ \\
\hline Tolimų metimu & Metimų tikslumas & $8,94 \pm 2,31$ & $9,72 \pm 2,24$ \\
\hline $\begin{array}{l}\text { Artimų metimu ir iš } \\
\text { vidutinio atstumo }\end{array}$ & Metimų tikslumas & $39,74 \pm 5,38$ & $45,36 * \pm 4,27$ \\
\hline $\begin{array}{l}\text { Kamuolio perdavimo } \\
\text { testas }\end{array}$ & $\begin{array}{l}\text { Kamuolio perdavimo } \\
\text { tikslumas }\end{array}$ & $32,8 \pm 5,92$ & $31,2 \pm 4,25$ \\
\hline
\end{tabular}

2 lentelè. Lengvesnès negalios (3-4,5 balụ) vežimèliụ krepšinio žaidèjų specialiųjų gebẻjimų testų rodikliai pritaikius vertikalios padèties vežimèli $(\overline{\mathbf{x}} \pm \mathbf{S} \overline{\mathbf{x}})$

Pastaba. * $-\mathrm{p}<0,05$, lyginant tos pačios grupès žaidejjų, sèdinčiu aukštame ir žemame vežimèlyje, rodiklius.

3 lentelè. Sunkesnès negalios $(\mathbf{1}-\mathbf{2 , 5}$ balų) vežimèliụ krepšinio žaidėjų specialiụjų gebẻjimų testų rodikliai pritaikius horizontalios padėties vežimèlį $(\bar{x} \pm S \bar{x})$

\begin{tabular}{|l|l|c|c|}
\hline \multicolumn{1}{|c|}{ Testas } & \multicolumn{1}{c|}{ Parametras } & Priekiné ratu padètis & Galinè ratu padėtis \\
\hline 30 s važiavimo, $\mathrm{m}$ & Anaerobinė ištvermé & $83,92 * \pm 4,03$ & $81,82 \pm 7,46$ \\
\hline $20 \mathrm{~m}$ sprinto, $\mathrm{s}$ & Greitumas & $6,58 \pm 0,47$ & $6,34 \pm 0,28$ \\
\hline Važiavimo aštuonetu & Vikrumas & $18,93 * \pm 1,82$ & $17,33 \pm 1,73$ \\
\hline $\begin{array}{l}\text { Kamuolio varymo } \\
\text { aštuonetu }\end{array}$ & $\begin{array}{l}\text { Vežimèlio ir kamuolio } \\
\text { valdymas }\end{array}$ & $16,62 * \pm 1,53$ & $15,67 \pm 1,09$ \\
\hline Tolimų metimu & Metimų tikslumas & $11,84 \pm 2,31$ & $10,92 \pm 2,24$ \\
\hline $\begin{array}{l}\text { Artimų metimų ir iš } \\
\text { vidutinio atstumo }\end{array}$ & Metimų tikslumas & $53,72 \pm 5,38$ & $49,68 \pm 4,27$ \\
\hline $\begin{array}{l}\text { Kamuolio perdavimo } \\
\text { testas }\end{array}$ & $\begin{array}{l}\text { Kamuolio perdavimo } \\
\text { tikslumas }\end{array}$ & $34,18 \pm 5,92$ & $33,23 \pm 4,25$ \\
\hline
\end{tabular}

4 lentelè. Lengvesnès negalios (3-4,5 balų) vežimèlių krepšinio žaidėjų specialiųjų gebẻjimų testų rodikliai pritaikius horizontalios padèties vežimèli $(\overline{\mathbf{x}} \pm \mathbf{S} \overline{\mathbf{x}})$

Pastaba. * $-\mathrm{p}<0,05$, lyginant tos pačios grupès žaidejjų, sẻdinčių galinès ir priekinès ratų padèties vežimèlyje, rodiklius.

vežimėlio pritaikymo. Vertikalios padėties vežimèlio pritaikymo tyrimas iš dalies patvirtino daugumos autorių keliamą prielaidą: žema sèdèsena pagerina vežimèlio aerodinamines savybes, dèl to sportininkai būna mobilesni, greitesni, vikresni (Wooten, 1992; Williams, 1994; Abu et al., 1998; Springle, 1998). Mūsų tyrimas parodè, kad žemai sẻdėdami geriau juda tik sunkesnès negalios žai- dẻjai, o lengvesnès - pasiekė panašių greitumo, vikrumo, anaerobinès ištvermès rodikliu sèdėdami aukštame ir žemame vežimèlyje. Lengvesnès negalios žaidejjų artimu, tolimų metimų i krepši ir iš vidutinio atstumo rodikliai buvo geresni, kai jie sėdejjo aukštame vežimèlyje. Šie duomenys sutampa su kitų tyrejjų gautaisiais (Brasile, 1986; Goosey-Tolfrey et al., 2002), tačiau mūsų tyrimas 
parodė, kad tik lengvesnès negalios žaidėjai geriau meta į krepši sẻdėdami aukštame vežimėlyje, o sunkesnès - netgi priešingai — geriau meta sèdėdami žemame vežimėlyje. Iš visų šių duomenu galima daryti išvada, kad pritaikius vertikalios padèties vežimèlị labai svarbu atsižvelgti ị žaidèjo pažeidos lygi ir negalios sunkumo laipsnị. Pirmiausia žaidèjas turi stabiliai sẻdèti vežimèlyje, tik paskui reikètų atsižvelgti $i$ jo ūgị ir kitus privalumus. Didesnio ūgio sunkesnès negalios žaidèjui taip pat rizikinga sėdèti vežimèlyje aukštai, nes jis praranda stabilumą ir dèl to sumažeja jo fizinių bei specialiuju gebejjimų galimybès, kurias jis galėtu realizuoti sėdeddamas žemiau.

Horizontalios padèties vežimèlio taikymas krepšinyje lemia du labai svarbius dalykus - vežimèlio stabilumą ir manevringumą (Abu et al., 1998). Galinè pagrindinių ratų padètis vežimèli daro stabilu̧, jis sunkiau virsta atgal, tačiau pasidaro mažiau manevringas posūkiuose (Adomaitienè ir kt., 2003). Kai vežimėlis priekinès pagrindinių ratų padėties, jis gali greitai virsti, pasidaro nestabilus judèdamas atgal, bet užtai labai manevringas posūkyje (Adomaitienè ir kt., 2003; Abu, et al., 1998). Ankstesni kitu autorių tyrimai parodé, kad sunkios negalios žaidèjams yra daug sunkiau atlikti vežimèlių krepšinio veiksmus ir valdyti vežimèli esant priekinei pagrindinių ratų padéčiai (Abu et al., 1998; Wooten, 1992). Ivvedus naują vežimèlių krepšinio taisyklę, leidžiančią vežimèlio gale naudoti apsaugini ratuka, ši problema išsisprendè. Mūsų gauti rezultatai sutampa su paskutinio V. Goosey-Tolfrey, D. Butterworth ir C. Morriss (2002) tyrimo duomenimis, teigiančiais, kad sunkesnès negalios žaidejjai gali būti manevringesni naudodami priekinès pagrindinių ratu padėties vežimèlį. Visgi sunkesnès negalios žaidejjų anaerobinès ištvermès ir greitumo rodikliai buvo geresni, kai jie sėdèjo galinès pagrindinių ratų padėties vežimėlyje. Priekinė pagrindinių ratų padėtis pagerino lengvesnès negalios žaidèjų anaerobinès ištvermès, vikrumo ir kamuolio varymo rodiklius, kiti buvo panašūs. Galima daryti prielaidą: pritaikius horizontalios padèties vežimèlị, sunkesnès negalios vežimèlių krepšinio žaidèjai gali rasti tinkamą padètị ir išnaudoti visas savo potencines galias. Šiuolaikinès vežimèlio pritaikymo galimybės sunkios negalios žaidejjams leidžia pasirinkti tokią padètị, kad vežimèlis būtų manevringas posūkyje ir greitai judètų tiesiojoje. Lengvesnès negalios žaidejjams geriau sèdèti priekinès pagrindinių ratu padèties vežimèlyje.

\section{IŠVADOS}

1. Tyrimo rezultatai parodè: kai sunkesnès negalios vežimėlio krepšinio žaidejjai sèdi žemame vežimėlyje, gerèja ju specialieji gebėjimai (greitumas, vikrumas, anaerobinè ištvermè, kamuolio varymas, artimi metimai ir iš vidutinio atstumo, kamuolio perdavimo tikslumas). Vertikalios padèties vežimèlio pritaikymas nepaveikè lengvesnès negalios žaidejju rezultatu.

2. Išryškèjo šios horizontalios vežimèlio padèties pritaikymo galimybès:

- kai sunkesnès negalios žaidèjas sėdi galinès pagrindinių ratų padèties vežimėlyje, gerejja jo anaerobinès ištvermès ir greitumo fizinių ypatybių raiška;

- kai sunkesnès negalios žaidejjas sèdi priekinès pagrindinių ratų padèties vežimèlyje, gerejja vikrumo ir kamuolio varymo rodikliai;

- kai lengvesnès negalios žaidejjas sèdi priekinès pagrindinių ratų padèties vežimèlyje, gerèja anaerobinès ištvermès, vikrumo ir kamuolio varymo rodikliai.

\section{LITERATŪRA}

Abu, B., Yilla, Roland, H., (1998). Setting up a whellchair for basketball. Sports'n Spokes, 2, 63-65.

Adomaitienè, R., Augustinaitytè-Jurčikonienė, G., Mikelkevičiūté, J. ir kt. (2003). Taikomoji neigaliuju fizine veikla. Kaunas: LKKA.

Brasile, F. M. \& Hedrick, B. N. (1996). The relationship of skills of elite wheelchair basketball competitors to the international functional classification system. Therapeutic Recreation Journal, 30 (2), 114-127.
Brasile, F. M. (1986). Wheelchair basketball skills proficiencies vs. NWBA classification. Adapted Physical Activity Quarterly, 3, 6-13.

Coubariaux, B. (1994). Wheelchair athletes classification system. IWBF.

Goosey-Tolfrey, V., Butterworth, D., Morriss, C. (2002). Free throw shooting technique of male wheelchair basketball players. Adapted Physical Activity Quarterly, 19 (2), 238-250. 
Hedrick, B., Byrnes, D., Shaver, L. (1994). Wheelchair Basketball. Paralyzed Veterans of America (2nd Edition). Washington.

Molik, B., Kosmol, A. (1999). Physical ability as a criteria in classifying basketball wheelchair players. Wychowanie fizyczne i sport, 1 (43), 471-472.

Skučas, K., Stonkus, S. (2002). Ivairiu amplua vežimèlių krepšinio žaidejjų žaidimo rodikliai. Sporto mokslas, 1 (27), 69-72.

Skučas, K., Stonkus, S. (2001). Vežimėliu krepšinio žaidèjų kai kurių fizinių ypatybių ir žaidimo igūdžių tyrimai. Ugdymas. Kūno Kultūra. Sportas, 4 (41), 74-80.
Springle, S. (1998). Biomechanical comparison of wheelchair basketball players and non-basketball players. Procedings of the Resna Annual Conference, Vol. 18, 170-172.

Williams, T. (1994). Socialization into wheelchair basketball in the United Kingdom: A structural functionalist perspective. Adapted Physical Activity Quarterly, 15 (4), $18-27$.

Wooten, M. (1992). Coaching basketball successfully. Champaign, IL: Leisure Press.

\title{
THE ROLE OF WHEELCHAIR ADJUSTMENT IN SPECIAL ABILITIES OF WHEELCHAIR BASKETBALL PLAYERS
}

\author{
Kęstutis Skučas \\ Lithuanian Academy of Physical Education, Kaunas, Lithuania
}

\begin{abstract}
The aim of the research was to dermine the role of wheelchair adjustment in special abilities of wheelchair basketball players. By method of testing 24 wheelchair basketball players participating in wheelchair basketball competitions were under research. The age of the participants of the research was $17-37$ years.

The following wheelchair basketball players participating in the research according to the International wheelchair basketball classification system were divided: two 1.5 point players, six -2 , two -2.5 , five 3 , five -4 , four -4.5 . Basic tests of special wheelchair basketball skills were used (Skučas, Stonkus, 2001; Hedrick, Byrnes, Shaver, 1994). Horizontal and two positions of vertical adjustment of wheelchair were carried out in purpose to evaluate the role of wheelchair adjustment in special abilities of wheelchair basketball players. With the purpose players participating in the research were divided into two groups: I - wheelchair basketball players with severe disability $1-2.5$ point players and II - non severe disability 3 -4.5 point players.

The research results revealed that wheelchair basketball players with severe disability showed better results in special abilities sitting in a low wheelchair possition. In this aspect there was no significant difference between the results of non severe disability players found. The research revealed that wheelchair basketball players with severe disability showed better results in aerobic endurance and speed performance sitting in a wheelchair with back main wheels position. Forward main wheels position of the wheelchair for wheelchair basketball players with severe disability showed better results in quickness and dribbling skills. Wheelchair basketball players with nonsevere disability showed better results in aerobic endurance, quickness and dribbling performance sitting in a wheelchair with forward main wheels position.
\end{abstract}

Keywords: wheelchair adjustment, vertical and horizontal position, low and high wheelchair position.

Gauta 2005 m. rugsėjo 27 d.

Received on September 27, 2005

Priimta 2006 m. vasario $20 \mathrm{~d}$.

Accepted on February 20, 2006
Kęstutis Skučas

Lietuvos kūno kultūros akademija

(Lithuanian Academy of Physical Education)

Sporto g. 6, LT-44221 Kaunas

Lietuva (Lithuania)

$\mathrm{Tel}+37037302660$

E-mail k.skucas@lkka.lt 